\title{
ANALISIS INDEKS AKTIVITAS GEOMAGNET PADA SAAT BADAI GEOMAGNET 13 OKTOBER 2016
}

\author{
M. Fakhrul Islam Masruri, Bayu Merdeka Tri Fristiyan Nanda \\ Sekolah Tinggi Meteorologi Klimatologi dan Geofisika,Tanggerang Selatan 15221 \\ *Email: fakhrulmasruri@gmail.com
}

\begin{abstract}
ABSTRAK
Badai geomagnet terjadi akibat aktivitas abnormal di matahari yang mempengaruhi intensitas angin matahari. Badai ini ditandai dengan perubahan nilai variasi harian medan magnet bumi yang besar, cepat dan tidak beraturan. Efek badai geomagnet di sekitar bumi dapat berdampak pada aktivitas manusia di luar angkasa dan di permukaan bumi. Salah satu kejadian badai geomagnet yang pernah tercatat adalah pada tanggal 13 Oktober 2016. Dalam penentuan tingkat gangguan geomagnet digunakan indeks geomagnet. Indeks geomagnet merupakan ukuran sederhana yang menggambarkan aktivitas magnetis yang berasal dari ionosfer dan magnetosfer bumi. Penelitian ini bertujuan untuk menganalisis indeks geomagnet ketika terjadi badai tanggal 13 Oktober 2016. Indeks geomagnet yang dianalisis antara lain indeks $K$, indeks A dan indeks Dst khususnya di wilayah Sumatera. Data yang digunakan adalah data variasi harian komponen H medan magnet bumi dari rekaman sensor magnetometer BMKG di Stasiun Gunungsitoli, Tuntungan, Sicincin, Liwa dan Tangerang. Berdasarkan hasil analisis dapat diidentifikasi jika badai geomagnet pada tanggal 13 Oktober 2016 tersebut termasuk kriteria badai geomagnet kuat jika ditinjau dari nilai Dst indeks yang menyentuh angka dibawah $-100 \mathrm{nT}$.
\end{abstract}

Kata kunci: indeks, badai, geomagnet

\begin{abstract}
Geomagnetic storms occur due to abnormal activity in the sun that affects the intensity of the solar wind. This storm is marked by changes in the value of daily variations of a large, fast and irregular magnetic field. The effects of geomagnetic storms around the earth can have an impact on human activity in outer space and on the earth's surface. One of the occurrences of geomagnetic storm ever recorded is on October 13, 2016. In determining the level of geomagnetic disturbance used geomagnetic index. The geomagnetic index is a simple measure that describes the magnetic activity derived from the ionosphere and the earth's magnetosphere. This study aims to analyze the geomagnetic index when the storm occurred on October 13, 2016. Geomagnetic indexes analyzed include $K$ index, $A$ index and Dst index, especially in the region of Sumatra. The data used are daily variation data of $H$ (horizontal) magnetic field component of BMKG magnetometer sensor record at Gunungsitoli station, Tuntungan station, Sicincin station, Liwa station and Tangerang station. Based on the results of the analysis can be identified if the geomagnetic storm on October 13, 2016 includes strong geomagnetic storm criteria when viewed from the Dst index value that touches the number below $-100 \mathrm{nT}$.
\end{abstract}

Keywords: geomagnetic, storm, index 


\section{PENDAhUluan}

Fenomena badai geomagnet dapat terjadi akibat aktivitas abnormal pada matahari sehingga mempengaruhi intensitas angin matahari ke antariksa. Aktivitas abnormal pada matahari tersebut antara lain disebabkan karena adanya fenomena lontaran massa korona atau dikenal dengan Coronal Mass Ejections (CME), adanya flare matahari (solar flares), dan fenomena lubang korona (coronal holes) (Basavaiah, 2011).

Lontaran massa korona (CME) merupakan peristiwa terlontarnya plasma dari matahari dalam jumlah besar dan membawa medan magnet. Ketika terjadi CME, partikel-partikel dan medan magnet dilontarkan ke antariksa terbawa oleh angin surya, kemudian angin surya yang menuju bumi akan bertumbukan dengan magnetosfer dan dapat terjadi injeksi energi medan listrik melalui mekanisme rekoneksi (Ballatore dan Gonzales, 2003). Energi tersebut akan menyebabkan pertumbuhan arus cincin di sekitar bumi yang memicu gangguan medan magnet bumi skala global atau badai geomagnet (Santoso, 2010). Sehingga dapat dikatakan CME merupakan salah satu penyebab terjadinya gangguan di ruang antar planet yang memicu terjadinya badai (Webb dkk., 2000) Namun tidak semua fenomena CME ini menyebabkan terjadinya badai geomagnet (Cane dkk., 2000).

Pada saat siklus matahari menurun, pengaruh lubang korona atau coronal holes sangat dominan pada medium antar planet, lubang korona tersebut akan bermigrasi dari daerah polar ke lintang yang lebih rendah bahkan kadang-kadang sampai ke ekuator matahari (Jackson, 1997). Migrasi lubang tersebut menghasilkan aliran plasma yang akan menerpa magnetosfer bumi dengan interval periodik dan akan menyebabkan badai geomagnet yang berulang (recurrent geomagnetic storms). Tetapi pada umumnya badai geomagnet tersebut hanya berkekuatan sedang (Tsurutani dkk., 1997). Kemudian untuk mengetahui aktivitas matahari yang berpengaruh pada bumi perlu dilakukan pengamatan terhadap CME dan flare secara kontinyu. Meskipun CME dan flare merupakan fenomena yang berbeda namun seringkali terjadi secara simultan. Dan pengamatan terhadap kedua fenomena tersebut menunjukkan bahwa CME dan flare berkaitan dengan kejadian badai geomagnet (Saroso, 2010).

Pengamatan mengenai badai geomagnet dilakukan pertama kali oleh Broun pada tahun 1861. Badai geomagnet diamati dengan melihat variasi intensitas komponen $\mathrm{H}$ medan magnet, jika terjadi penurunan intensitas secara signifikan maka dapat diindikasi terjadi badai. Selanjutnya pada penelitian Moos di tahun 1910 barulah dapat diidentifikasi pola badai geomagnet, yaitu terjadi peningkatan mendadak komponen $\mathrm{H}$ medan magnet kemudian diikuti dengan penurunan yang besar, cepat dan tidak beraturan selama beberapa jam lalu diakhiri dengan pemulihan yang lambat selama 2-3 hari. Terdapat efek serius yang ditimbulkan oleh badai geomagnet yakni dapat mengganggu aktivitas manusia di bumi maupun di luar angkasa.

Tingkat aktivitas gangguan geomagnet akibat proses interaksi badai geomagnet pada magnetosfer dan ionosfer dampaknya dinyatakan dengan indeks aktivitas geomagnet. Indeks aktivitas geomagnet adalah ukuran sederhana dari aktivitas geomagnet yang terjadi di magnetosfer dan ionosfer bumi selama periode kurang dari beberapa jam yang dicatat oleh observatorium. Indeks yang digunakan untuk mengukur seberapa besar kekuatan badai geomagnet yang disebut Disturbance storm time index (indeks Dst). Indeks Dst menggambarkan gangguan pada komponen $\mathrm{H}$ medan magnet ketika terjadi badai geomagnet khususnya pada daerah lintang rendah atau ekuator. Kemudian indeks geomagnet secara lokal (pada suatu lokasi tertentu) dinyatakan dengan indeks $\mathrm{K}$, dimana indeks $\mathrm{K}$ menggambarkan seberapa besar efek yang ditimbulkan oleh aktivitas matahari terhadap gangguan medan magnet di permukaan bumi. Sedangkan indeks A merupakan nilai konversi rata-rata indeks $\mathrm{K}$ yang digunakan untuk menentukan kriteria badai geomagnet.

\section{METODE PENELITIAN}

Kejadian badai geomagnet yang dianalisis adalah badai geomagnet pada tanggal 13 
Oktober 2016. Berdasarkan arsip Space Weather Live GFZ Postdam, Jerman, bahwa badai 13 Oktober 2016 tercatat sebagai salah satu dari Top 50 geomagnetic storms of 2016 atau salah satu dari 50 badai geomagnet terkuat yang pernah tercatat di tahun 2016. Dengan nilai Dst minimum WDC Kyoto sebesar -104 nT yang berarti termasuk dalam kriteria badai kuat berdasarkan indeks Dstnya.

Kemudian data geomagnet yang digunakan dalam penelitian ini berasal dari rekaman jaringan sensor magnetometer BMKG Sumatera dan Jawa Bagian Barat pada tanggal 10-16 Oktober 2016.

Tabel 1. Sensor magnetometer yang digunakan dalam penelitian.

\begin{tabular}{|c|c|c|c|}
\hline Stasiun & Lokasi & $\begin{array}{c}\text { Tipe } \\
\text { Magnetomete } \\
\text { r }\end{array}$ & $\begin{array}{c}\text { Komp } \\
\text { yang } \\
\text { diuku } \\
\mathbf{r}\end{array}$ \\
\hline $\begin{array}{l}\text { Tuntungan } \\
\text { (TUN) }\end{array}$ & $\begin{array}{c}3.500^{\circ} \\
\mathrm{LU}- \\
98.56^{\circ} \\
\mathrm{BT}\end{array}$ & Lemi-018 & $\begin{array}{l}\mathrm{X}, \mathrm{Y}, \\
\mathrm{Z}, \mathrm{F}\end{array}$ \\
\hline $\begin{array}{l}\text { Gunungsitol } \\
\text { i (GSI) }\end{array}$ & $\begin{array}{c}1.304^{\circ} \\
\mathrm{LU}- \\
97.57^{\circ} \\
\mathrm{BT}\end{array}$ & Magdas-9 & $\begin{array}{l}\mathrm{H}, \mathrm{D}, \\
\mathrm{Z}, \mathrm{F}\end{array}$ \\
\hline $\begin{array}{l}\text { Sicincin } \\
\text { (SCN) }\end{array}$ & $\begin{array}{c}0.550^{\circ} \\
\mathrm{LS}- \\
100.30 \\
{ }^{\circ} \mathrm{BT}\end{array}$ & Magdas-9 & $\begin{array}{l}\mathrm{H}, \mathrm{D}, \\
\mathrm{Z}, \mathrm{F}\end{array}$ \\
\hline $\begin{array}{l}\text { Liwa } \\
\text { (LWA) }\end{array}$ & $\begin{array}{c}5.020^{\circ} \\
\mathrm{LS}- \\
104.06 \\
{ }^{\circ} \mathrm{BT}\end{array}$ & Magdas-9 & $\begin{array}{l}\mathrm{H}, \mathrm{D}, \\
\mathrm{Z}, \mathrm{F}\end{array}$ \\
\hline $\begin{array}{l}\text { Tangerang } \\
\text { (TNG) }\end{array}$ & $\begin{array}{c}6.172^{\circ} \\
\mathrm{LS}- \\
106.65 \\
{ }^{\circ} \mathrm{BT}\end{array}$ & Lemi-018 & $\begin{array}{l}\mathrm{X}, \mathrm{Y}, \\
\mathrm{Z}, \mathrm{F}\end{array}$ \\
\hline
\end{tabular}

Sensor Magdas-9 dan Lemi-018 tersebut memiliki sampling rate sebesar 1 detik dengan ketelitian 0.01 nT. Dari raw data yang diperoleh berupa nilai komponen medan magnet per detik, dipilih data pada komponen $\mathrm{H}$ medan magnet untuk selanjutnya dianalisis. Khusus untuk sensor Lemi-018 dengan orientasi pengukuran komponen $\mathrm{X}, \mathrm{Y}, \mathrm{Z}$, maka dicari dulu komponen $\mathrm{H}$ dengan penjumlahan vektor.

$$
\begin{aligned}
& H^{2}=X^{2}+Y^{2} \\
& H=\sqrt{X^{2}+Y^{2}}
\end{aligned}
$$

Selanjutnya dari komponen $\mathrm{H}$ medan magnet tersebut dapat ditentukan indeks Dst masingmasing stasiun. Indeks Dst merupakan selisih dari data komponen $\mathrm{H}$ asli dengan data komponen $\mathrm{H}$ pada data trend atau pola hari tenang medan magnet (quite day). Penentuan pola hari tenang didasarkan pada hasil dekomposisi sinyal menggunakan metode EMD (Empirical mode decomposition).

Metode EMD ini digunakan untuk mendapatkan pola atau trend data hari tenang (quite day) atau hari dimana tidak terdapat gangguan medan magnet pada magnetosfer dan ionosfer. Secara sederhananya, cara kerja metode ini adalah dengan mencari rata-rata antara semua puncak maksimum dan semua puncak minimum dari suatu sinyal yang telah dihubungkan masing-masing puncaknya oleh garis spline kubik, kemudian hasil rata-rata tersebut dihitung ulang dengan prosedur yang sama sedemikian rupa agar memperoleh pola atau trend yang halus atau smooth.

Dalam hal EMD ini penulis menggunakan aplikasi "Program Analisa Trend Harian Data Magnet Bumi" oleh M. Syirojudin BMKG (2015). Data yang digunakan sebagai trend juga harus diperhatikan agar sekiranya data harian tersebut tidak terdapat gangguan medan magnet sehingga hasil analisis indeks geomagnet yang diperoleh akurat.

Setelah diperoleh pola hari tenang, maka data variasi harian komponen $\mathrm{H}$ medan magnet hasil rekaman sensor dikurangi dengan data komponen $\mathrm{H}$ medan magnet pada hari tenangnya, kemudian data hasil selisih per detik tersebut dirata-rata per jam sehingga diperoleh nilai indeks Dst per jamnya. Data indeks Dst per jam yang telah didapat kemudian diambil amplitudo maksimumnya setiap 3 jam lalu dikonversi dengan skala indeks $\mathrm{K}$ yang sesuai dengan daerah lintang rendah seperti ditunjukkan pada Tabel 2 berikut. 
Tabel 2. Konversi fisis tingkat gangguan geomagnet/indeks Dst per-jam dalam nanoTesla

(nT) ke dalam skala indeks $\mathrm{K}$ dan indeks a (amplitudo) (Syirojudin, 2016).

\begin{tabular}{|c|c|c|}
\hline $\begin{array}{c}\text { Rentang Nilai Dst } \\
\text { (nT) }\end{array}$ & $\begin{array}{c}\text { Indeks } \\
\mathbf{K}\end{array}$ & $\begin{array}{c}\text { Indeks } \\
\mathbf{a}\end{array}$ \\
\hline $0-3.5$ & 0 & 0 \\
\hline $3.5-7$ & 1 & 3 \\
\hline $7-13$ & 2 & 7 \\
\hline $13-25$ & 3 & 15 \\
\hline $25-41$ & 4 & 27 \\
\hline $41-71$ & 5 & 48 \\
\hline $71-121$ & 6 & 80 \\
\hline $121-201$ & 7 & 140 \\
\hline $201-300$ & 8 & 240 \\
\hline$>300$ & 9 & 400 \\
\hline
\end{tabular}

Indeks $\mathrm{K}$ adalah sebuah indeks lokal kuasi logaritmik dalam periode 3 jam dari aktivitas magnetik bumi. Diperoleh dari konversi nilai indeks Dst per 3 jam mengacu pada Tabel 2. Indeks a (amplitudo) adalah konversi linier dari indeks $\mathrm{K}$ dalam periode $3 \mathrm{jam}$, nilai konversinya ditunjukkan pada Tabel 2 diatas.

Indeks A didefinisikan sebagai nilai maksimum yang terjadi dalam rentang waktu 24 jam, dimana diperoleh dengan menghitung rata-rata dari 8 titik amplitudo (indeks a). Kriteria badai geomagnet yang ditentukan berdasarkan indeks A ditunjukkan pada Tabel 3 berikut.

Tabel 3. Kriteria badai geomagnet berdasarkan nilai indeks A (Loewe dan Prolss,1997).

\begin{tabular}{|c|c|}
\hline Rentang Nilai Indeks A & Kriteria Badai \\
\hline $0<\mathrm{A}<30$ & Relatif tenang \\
\hline $30<\mathrm{A}<50$ & Badai lemah \\
\hline $50<\mathrm{A}<100$ & Badai sedang \\
\hline $\mathrm{A}>100$ & Badai kuat \\
\hline
\end{tabular}

Adapun tingkat kuat badai geomagnet berdasarkan nilai indeks Dst dikelompokkan menurut kriteria Loewe dan Prolss (1997) ditunjukkan pada Tabel 4 berikut.

Tabel 4. Klasifikasi intensitas badai geomagnet berdasarkan indeks dst.

\begin{tabular}{|c|c|}
\hline $\begin{array}{c}\text { Rentang Nilai Indeks } \\
\text { Dst }\end{array}$ & $\begin{array}{c}\text { Kriteria } \\
\text { Badai }\end{array}$ \\
\hline$-30 \mathrm{nT}>$ Dst $>-50 \mathrm{nT}$ & Badai lemah \\
\hline$-50 \mathrm{nT}>\mathrm{Dst}>-100 \mathrm{nT}$ & Badai sedang \\
\hline$-100 \mathrm{nT}>\mathrm{Dst}>-200 \mathrm{nT}$ & Badai kuat \\
\hline$-200 \mathrm{nT}>\mathrm{Dst}>-300 \mathrm{nT}$ & $\begin{array}{c}\text { Badai sangat } \\
\text { kuat }\end{array}$ \\
\hline Dst < -300 nT & Badai ekstrim \\
\hline
\end{tabular}

\section{HASIL DAN PEMBAHASAN}

\subsection{Analisis Indeks K Geomagnet}

Berdasarkan hasil pengolahan data, diperoleh tingkat gangguan medan magnet berupa indeks $\mathrm{K}$ (lokal) pada masing-masing daerah stasiun pengamatan seperti ditunjukkan pada Gambar 1 berikut ini. 


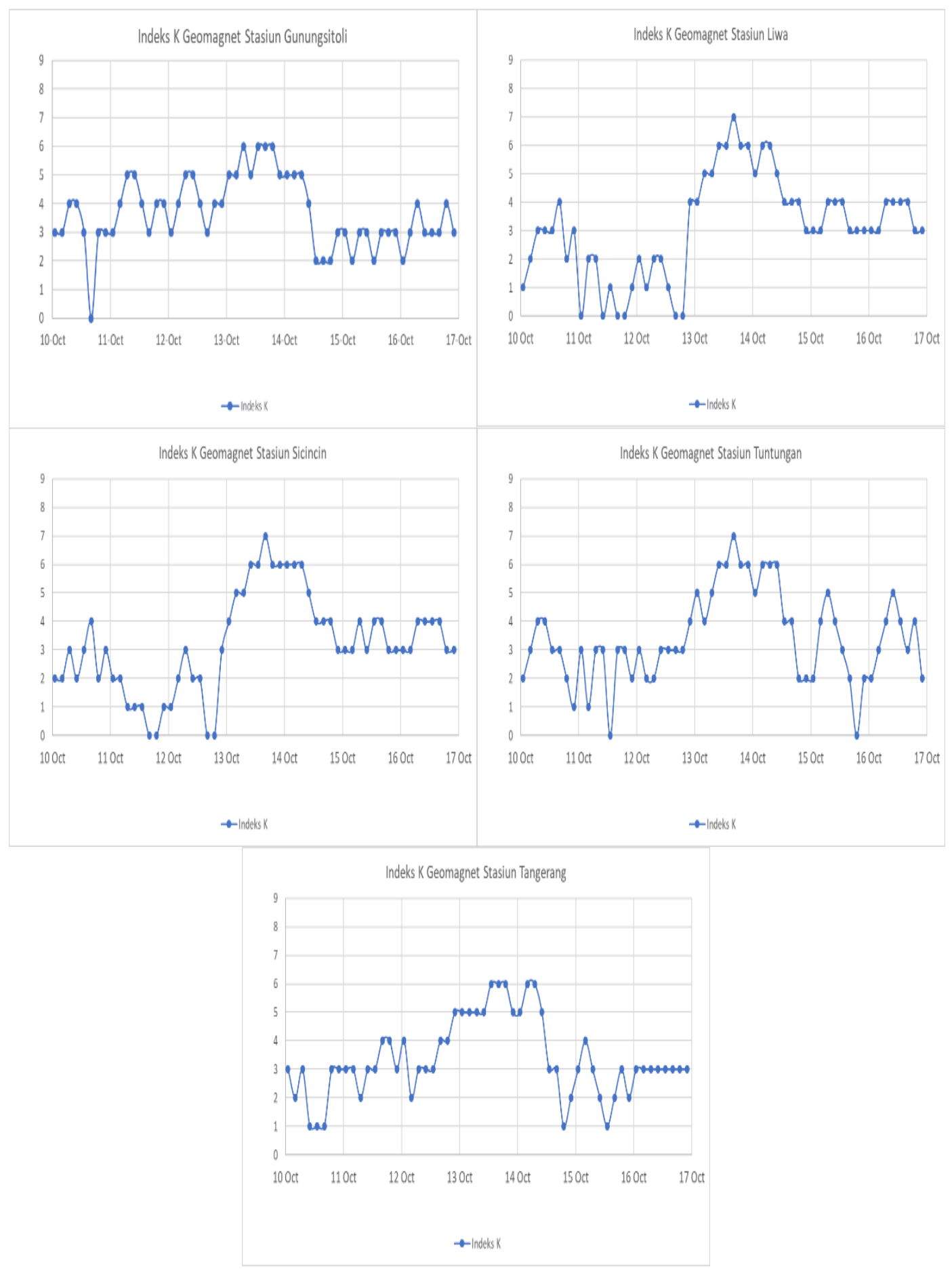

Gambar 1. Grafik nilai indeks K lokal pada masing-masing stasiun pengamatan yang merepresentasikan tingkat gangguan geomagnet pada wilayah Sumatera dan Jawa Bagian Barat pada tanggal 10-16 Oktober 2016. 
Dapat dilihat dari lima grafik diatas mengenai indeks $\mathrm{K}$ yang tercatat oleh masing-masing stasiun pengamatan bahwa indeks $\mathrm{K}$ bernilai tinggi pada saat kejadian badai geomagnet 13 Oktober 2016, yang menandakan besarnya tingkat gangguan medan magnet yang terjadi pada magnetosfer dan ionosfer bumi. Klasifikasi badai geomagnet berdasarkan indeks $\mathrm{K}$ tertinggi yang tercatat pada hari tersebut ditunjukkan pada Tabel 5 berikut ini.

Tabel 5. Klasifikasi intensitas badai geomagnet dengan pengukuran fisis indeks $\mathrm{K}$.

\begin{tabular}{|c|c|c|}
\hline Skala & Pengukuran Fisis & Kriteria Badai \\
\hline $\mathrm{G} 1$ & $\mathrm{~K}=5$ & Badai lemah \\
\hline $\mathrm{G} 2$ & $\mathrm{~K}=6$ & Badai sedang \\
\hline $\mathrm{G} 3$ & $\mathrm{~K}=7$ & Badai kuat \\
\hline $\mathrm{G} 4$ & $\mathrm{~K}=8$ & Badai sangat kuat \\
\hline $\mathrm{G} 5$ & $\mathrm{~K}=9$ & Badai ekstrim \\
\hline
\end{tabular}

Sehingga jika dikaitkan dengan indeks $\mathrm{K}$ yang tercatat pada masing-masing stasiun pengamatan di wilayah Sumatera dan Jawa Bagian Barat, maka kriteria badai geomagnet di masing-masing daerah yang diwakili (secara lokal) ditunjukkan dengan Tabel 6 berikut ini.

Tabel 6. Identifikasi kriteria badai geomagnet ditinjau dari indeks $\mathrm{K}$ tertinggi yang tercatat pada stasiun pengamatan di wilayah Sumatera dan Jawa

Bagian Barat selama 10-16 Oktober 2016.

\begin{tabular}{|c|c|c|}
\hline Stasiun & $\begin{array}{c}\text { Indeks K } \\
\text { Tertinggi }\end{array}$ & $\begin{array}{c}\text { Kriteria } \\
\text { Badai }\end{array}$ \\
\hline $\begin{array}{c}\text { Tuntungan } \\
\text { (TUN) }\end{array}$ & $\mathrm{K}=7$ & Badai kuat \\
\hline $\begin{array}{c}\text { Gunungsitoli } \\
\text { (GSI) }\end{array}$ & $\mathrm{K}=6$ & $\begin{array}{c}\text { Badai } \\
\text { sedang }\end{array}$ \\
\hline Sicincin (SCN) & $\mathrm{K}=7$ & Badai kuat \\
\hline $\begin{array}{c}\text { Liwa (LWA) } \\
\text { Tangerang } \\
\text { (TNG) }\end{array}$ & $\mathrm{K}=6$ & $\begin{array}{c}\text { Badai kuat } \\
\text { sedang }\end{array}$ \\
\hline
\end{tabular}

Didapatkan hasil analisis bahwa berdasarkan indeks K geomagnet, badai 13 Oktober 2016 tergolong kriteria badai geomagnet tingkat kuat dengan nilai $\mathrm{K}$ tertinggi yang tercatat pada stasiun pengamatan sebesar $\mathrm{K}=7$ (skala G3).

\subsection{Analisis Indeks A Geomagnet}

Berdasarkan hasil konversi indeks $\mathrm{K}$, diperoleh nilai indeks A pada masing-masing stasiun pengamatan geomagnet seperti ditunjukkan pada Gambar 2 berikut ini.

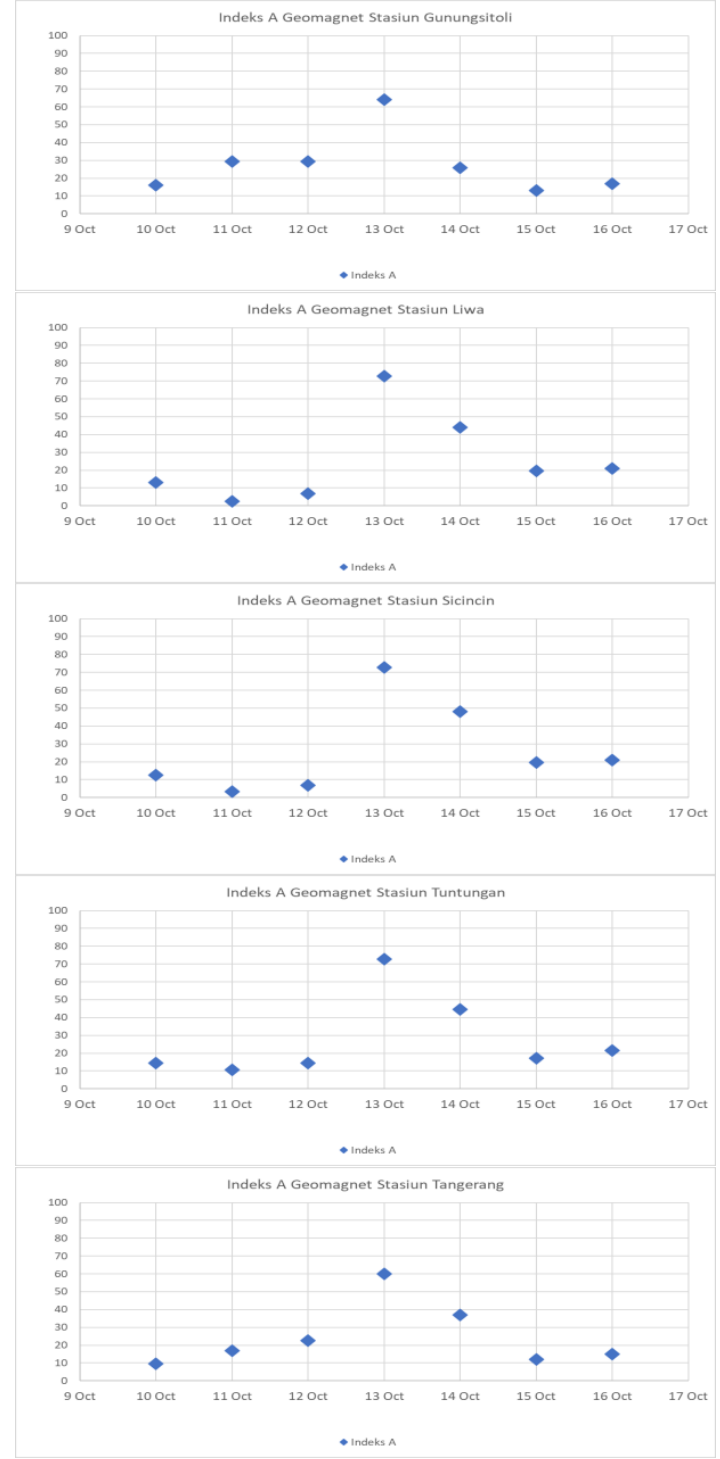

Gambar 2. Grafik nilai indeks A berdasarkan hasil konversi indeks $\mathrm{K}$ pada masing-masing stasiun pengamatan pada rentang waktu 10-16 Oktober 2016.

Indeks A diperoleh dari hasil rata-rata dari 8 titik amplitudo (indeks a) yang merupakan konversi linier dari indeks $\mathrm{K}$ dalam periode tiga jam. Berdasarkan Gambar 2 diatas, ditunjukkan bahwa nilai indeks A tertinggi yang tercatat oleh stasiun pengamatan di wilayah Sumatera dan Jawa Bagian Barat berada tepat pada saat kejadian badai geomagnet 13 Oktober 2016. Kemudian jika dikaitkan dengan kriteria badai geomagnet berdasarkan nilai indeks A yang ditunjukkan pada Tabel 3 di pembahasan 
sebelumnya, maka dapat diperoleh rincian hasil analisis indeks A sebagai berikut ditunjukkan pada Tabel 7.

Tabel 7. Identifikasi kriteria badai geomagnet ditinjau dari indeks A tertinggi yang tercatat pada stasiun pengamatan di wilayah Sumatera dan Jawa

Bagian Barat selama 10-16 Oktober 2016.

\begin{tabular}{|c|c|c|}
\hline Stasiun & $\begin{array}{c}\text { Indeks A } \\
\text { Tertinggi }\end{array}$ & $\begin{array}{c}\text { Kriteria } \\
\text { Badai }\end{array}$ \\
\hline $\begin{array}{c}\text { Tuntungan } \\
\text { (TUN) }\end{array}$ & $\mathrm{A}=72.875$ & $\begin{array}{c}\text { Badai } \\
\text { sedang }\end{array}$ \\
\hline $\begin{array}{c}\text { Gunungsitoli } \\
\text { (GSI) }\end{array}$ & $\mathrm{A}=64$ & $\begin{array}{c}\text { Badai } \\
\text { sedang }\end{array}$ \\
\hline Sicincin (SCN) & $\mathrm{A}=72.875$ & $\begin{array}{c}\text { Badai } \\
\text { sedang }\end{array}$ \\
\hline Liwa (LWA) & $\mathrm{A}=72.875$ & $\begin{array}{c}\text { Badai } \\
\text { sedang }\end{array}$ \\
\hline $\begin{array}{c}\text { Tangerang } \\
\text { (TNG) }\end{array}$ & $\mathrm{A}=60$ & $\begin{array}{c}\text { Badai } \\
\text { sedang }\end{array}$ \\
\hline
\end{tabular}

\subsection{Analisis Indeks Dst Geomagnet}

Berdasarkan hasil selisih antara komponen $\mathrm{H}$ geomagnet hasil observasi dengan komponen $\mathrm{H}$ geomagnet pola hari tenang, maka didapatlah nilai indeks Dst (Disturbance storm time) yang menunjukkan tingkat besarnya gangguan medan magnet yang terjadi pada magnetosfer dan ionosfer bumi atau biasa dipakai untuk menilai seberapa besar kekuatan badai geomagnet yang terjadi.

Hasil pengolahan didapat sebagai berikut ditunjukkan pada Gambar 3 diatas yang menunjukkan grafik indeks Dst pada masingmasing stasiun pengamatan di wilayah Sumatera dan Jawa Bagian Barat pada rentang waktu periode 10-16 Oktober 2016. Berdasarkan Gambar 3 diatas dapat diketahui terdapat pola yang sama antara kelima stasiun pengamatan geomagnet tersebut, jika terdapat penurunan nilai Dst secara derastis ketika terjadi badai geomagnet 13 Oktober 2016.

Pola yang teramati sama persis dengan pernyataan Moos pada tahun 1910 bahwa terjadi peningkatan mendadak komponen medan magnet kemudian diikuti dengan penurunan yang signifikan selama beberapa jam lalu diakhiri dengan pemulihan yang lambat selama 2-3 hari. Menandakan hal tersebut adalah ciri-ciri atau tanda-tanda telah terjadinya badai geomagnet yang signifikan pada magnetosfer dan ionosfer bumi yang tercatat oleh stasiun pengamatan geomagnet di permukaan bumi.

Secara rinci dapat ditunjukkan pada Tabel 8 di bawah ini, mengenai kriteria badai geomagnet jika berdasarkan pada nilai indeks Dst serta detail nilai amplitudo minimum Dst yang tercatat pada kejadian badai 13 Oktober 2016. Yang akan dikaitkan dengan penggolongan kekuatan badai berdasarkan indeks Dst (Loewe dan Prolss 1997) yang ditunjukkan pada Tabel 4 diatas di pembahasan sebelumnya.
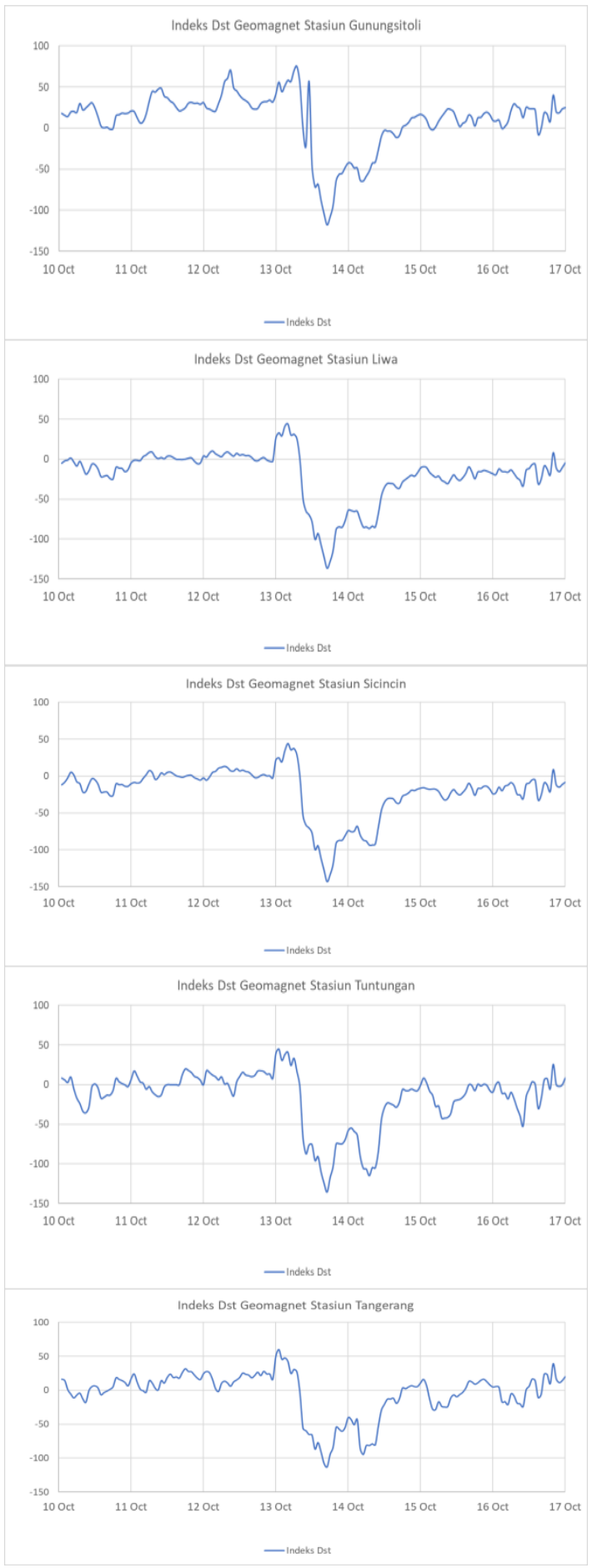
Gambar 3. Grafik nilai indeks Dst pada stasiun pengamatan rentang waktu 10-16 Oktober 2016.

Tabel 8. Identifikasi kriteria badai geomagnet ditinjau dari indeks Dst terendah yang tercatat pada stasiun pengamatan di wilayah Sumatera dan Jawa

Bagian Barat selama 10-16 Oktober 2016.

\begin{tabular}{|c|c|c|c|}
\hline Stasiun & Waktu & $\begin{array}{c}\text { Indeks Dst } \\
\text { Terendah }\end{array}$ & $\begin{array}{c}\text { Kriteria } \\
\text { Badai }\end{array}$ \\
\hline $\begin{array}{c}\text { Tuntungan } \\
(\text { TUN) }\end{array}$ & $\begin{array}{c}13 \mathrm{Okt}, \\
17 \mathrm{UTC}\end{array}$ & $\begin{array}{c}\mathrm{Dst}=- \\
135.46 \mathrm{nT}\end{array}$ & $\begin{array}{c}\text { Badai } \\
\text { kuat }\end{array}$ \\
\hline $\begin{array}{c}\text { Gunungsitoli } \\
(\mathrm{GSI})\end{array}$ & $13 \mathrm{Okt}$, & $\begin{array}{c}\mathrm{Dst}=- \\
118.15 \mathrm{nT}\end{array}$ & $\begin{array}{c}\text { Badai } \\
\text { kuat }\end{array}$ \\
\hline $\begin{array}{c}\text { Sicincin } \\
(\mathrm{SCN})\end{array}$ & $13 \mathrm{Okt}$, & $\begin{array}{c}\mathrm{Dst}=- \\
143.04 \mathrm{nT}\end{array}$ & $\begin{array}{c}\text { Badai } \\
\text { kuat }\end{array}$ \\
\hline $\begin{array}{c}\text { Liwa (LWA) } \\
17 \mathrm{UTC}\end{array}$ & $17 \mathrm{Okt}$, & $\begin{array}{c}\mathrm{Dst}=- \\
136.67 \mathrm{nT}\end{array}$ & $\begin{array}{c}\text { Badai } \\
\text { kuat }\end{array}$ \\
\hline $\begin{array}{c}\text { Tangerang } \\
(\mathrm{TNG})\end{array}$ & $13 \mathrm{Okt}$, & $\mathrm{Dst}=-$ & $\begin{array}{c}\text { Badai } \\
\text { kuat }\end{array}$ \\
\hline
\end{tabular}

Berdasarkan Tabel 8 diatas, kejadian badai geomagnet tercatat tepat pada 13 Oktober 2016 jam 17.00 UTC, dimana semua stasiun pengamatan geomagnet yang digunakan menunjukkan hasil yang sama. Hasil tersebut adalah puncak minimum atau nilai Dst terendah dari masing-masing stasiun pencatat berada pada satu waktu sehingga dapat dikatakan akurat. Dengan rincian pada Tabel 8 diatas menunjukkan jika kriteria badai geomagnet 13 Oktober 2016 menyentuh angka Dst dibawah $100 \mathrm{nT}$, sehingga tergolong kategori badai kuat menurut kriteria Loewe dan Prolss 1997.

\section{KESIMPULAN}

Berdasarkan hasil analisis indeks $\mathrm{K}$, kejadian badai geomagnet 13 Oktober 2016 termasuk kriteria badai geomagnet yang kuat $(\mathrm{K}=7)$ dengan nilai $\mathrm{K}$ tertinggi sebesar $\mathrm{K}=7$. Berbeda dengan hasil analisis indeks A, kejadian badai geomagnet 13 Oktober 2016 termasuk kriteria badai geomagnet yang sedang $(50<\mathrm{A}<100)$ dengan nilai $A$ tertinggi sebesar $A=72.875$. Sedangkan jika ditinjau dari indeks Dst, maka kejadian badai geomagnet 13 Oktober 2016 termasuk kriteria badai geomagnet yang kuat $(-100$ nT $>$ Dst $>-200 \quad n T)$ dengan nilai Dst terendah mencapai Dst $=-143.04 \mathrm{nT}$.

\section{UCAPAN TERIMA KASIH}

Ucapan terima kasih penulis sampaikan kepada Bapak Suaidi Ahadi, Bapak Muhammad Syirojudin, Bidang Geofisika Potensial BMKG dan Pusat Sains Antariksa LAPAN.

\section{DAFTAR PUSTAKA}

Basavaiah. 2011. Geomagnetism: Solid Earth and Upper Atmosphere Perspectives.167.

Ballatore dan Gonzales, W. D. 2003. On the estimates of ring current injection and decay, Earth Planets Space 55.427-435.

Santoso 2010. Identifikasi kondisi angin surya (solar wind) untuk prediksi badai geomagnet, Prosiding Pertemuan Imiah XXIV HFI Jateng \& DIY 2010, Semarang, pp. 275-283.

Webb, F. 2000. Journal of Geophysical Research 105.7491.

Cane, V. 2000. Geophysical Research Letters 27. 3591.

Jackson, V. 1997. Heliospheric observations of solar disturbances and their potential role in the origin of storms, Magnetic Storms Mon. Ser. Vol. 98. p. 59.

Tsurutani, T. 1995. Large amplitude IMF luctuations in corotating interaction regions: Ulysses at midlatitudes, Geophysical Research Letters 22. 3397.

Saroso. 2010. Karakteristik badai geomagnet besar dalam siklus matahari ke-22 dan 23, Prosiding Pertemuan Ilmiah XXIV HFI Jateng \& DIY 2010, Semarang, pp. 190194.

Syirojudin. 2016. Aplikasi pengolahan data magnet bumi untuk menunjang pelayanan informasi medan magnet bumi yang mudah dipahami masyarakat. Pusat Seismologi Teknik Geofisika Potensial dan Tanda Waktu BMKG. (http://www.bmkg.go.id/geofisikapotensial/magnet-bumi.bmkg diakses pada tanggal 16 Maret 2018.)

Loewe, A., dan Prolss, G. W. 1997. Classification and mean behavior of magnetic storms, Journal of Geophysical Research 102.14209-1421. 